$$
\text { CONF-960569--17 }
$$

\title{
IMPURITY FEEDBACK CONTROL FOR ENHANCED DIVERTOR AND EDGE RADIATION IN DIII-D DISCHARGES
}

\author{
by
G.L. JACKSON, G.M. STAEBLER, S.L. ALLEN, N.H. BROOKS, \\ T.E. EVANS, J.R. FERRON, A.W. LEONARD, R. MAINGI, \\ T.W. PETRIE, M.J. SCHAFFER, R.D. WOOD, W.P. WEST, \\ and D.G. WHYTE
}

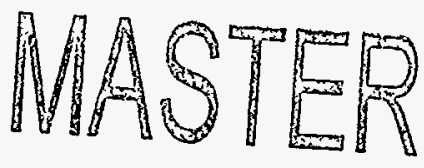

NISTRIEUTION OF THS DOCUSEMT IS UNLLMTED 


\section{DISCLAIMER}

This report was prepared as an account of work sponsored by an agency of the United States Government. Neither the United States Government nor any agency thereof, nor any of their employees, makes any warranty, express or implied, or assumes any legal liability or responsibility for the accuracy, completeness, or usefulness of any information, apparatus, product, or process disclosed, or represents that its use would not infringe privately owned rights. Reference herein to any specific commercial product, process, or service by trade name, trademark, manufacturer, or otherwise, does not necessarily constitute or imply its endorsement, recommendation, or favoring by the United States Government or any agency thereof. The views and opinions of authors expressed herein do not necessarily state or reflect those of the United States Government or any agency thereof. 


\title{
IMPURITY FEEDBACK CONTROL FOR ENHANCED DIVERTOR AND EDGE RADIATION IN DIII-D DISCHARGES
}

\author{
by \\ G.L. JACKSON, G.M. STAEBLER, S.L. ALLEN, ${ }^{\dagger}$ N.H. BROOKS, \\ T.E. EVANS, J.R. FERRON, A.W. LEONARD, R. MAINGI, \\ T.W. PETRIE, M.J. SCHAFFER, R.D. WOOD, † W.P. WEST, \\ and D.G. WHYTE $\triangle$
}

This is a preprint of a paper to be presented at the 12th International Conference on Plasma Surface Interactions on Controlled Fusion Devices, May 20-24, 1996, Saint-Raphael, France and to be published in the Proceedings.

†Lawrence Livermore National Laboratory Ғoak Ridge National Laboratory

$\checkmark$ INRS - Energie et Materiaux

\author{
Work supported by \\ the U.S. Department of Energy \\ under Contract Nos. DE-AC03-89ER51114, W-7405-ENG-48, \\ and DE-AC05-960R22464
}

GA PROJECT 3466 OCTOBER 1996 
700mmop:

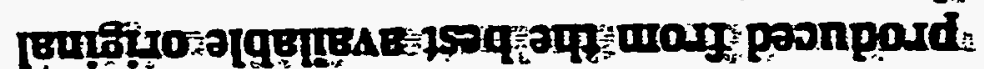

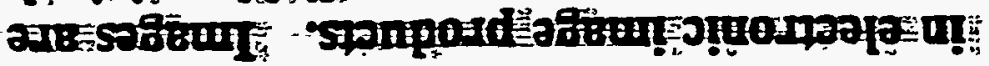

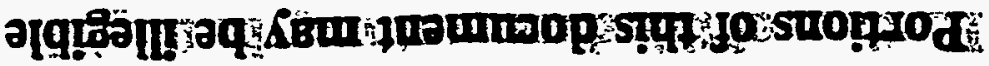

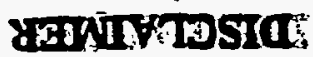




\section{INTRODUCTION}

Long pulse and steady state fusion ignition devices will require a significant radiated power fraction to minimize heat flux to, and sputtering of, the first wall. While impurity gases have been proposed to enhance radiation, precise control of impurity gas injection is essential to achieve an adequate radiative power fraction while maintaining good energy confinement and low central impurity concentration. We report here the first experiments in the DIII-D tokamak using feedback control of the rate of impurity gas injection. These experiments were carried out with active divertor pumping using the in-situ DIII-D cryopump. The radiated power fraction was controlled by sensing either $\mathrm{U}-\mathrm{V}$ edge line radiation $\left(\mathrm{Ne}^{+7}\right)$ or mantle radiation from selected bolometer channels and using the DIII-D digital plasma control system to calculate radiated power real-time and generate an error signal to control an impurity gas injector valve.

Impurity radiation has been used on other devices to obtain low heat flux to plasma facing surfaces while maintaining good energy and particle confinement in the plasma core without excessive impurity contamination. The TEXTOR tokamak has used siliconization and neon gas puffing to obtain a highly radiative mantle while maintaining energy confinement significantly above the ITER 89P L-mode empirical scaling relation [1,2]. More recently, the ASDEX-U tokamak has demonstrated $\mathrm{H}$-mode confinement in a diverted discharge under completely detached conditions ( $\mathrm{CDH}$-mode).

In this paper we present the implementation of a feedback control method which uses either bolometer signals or U-V impurity line radiation to control the fueling rate of a main chamber neon injector. Using this hardware, we have successfully controlled the fraction of radiated power and obtained energy confinement above ITER-89P L-mode scaling for radiated power fractions, $\mathrm{P}_{\mathrm{fr}}, \gtrsim 90 \%$. Transient phases of the $\mathrm{CDH}$-mode have been observed with energy confinement enhancements, $\tau_{\mathrm{E}} / \tau_{\mathrm{ITER}-89 \mathrm{P}} \leq 1.6$. In this paper we define the fraction of radiated power, $\mathrm{P}_{\mathrm{fr}}=\mathrm{P}_{\mathrm{rad}} /\left(\mathrm{P}_{\mathrm{tot}}-\mathrm{dW} \mathrm{MHD}_{\mathrm{MH}} / \mathrm{dt}\right)$, where $\mathrm{P}_{\mathrm{rad}}$ is the total radiated power including divertor radiation measured by a 48 channel bolometer system, $P_{\text {tot }}$ is the total input power from neutral beam injection and ohmic heating, and $\mathrm{W}_{\mathrm{MHD}}$ is the plasma stored energy. 


\section{THE DIII-D IMPURITY FEEDBACK CONTROL SYSTEM}

For the discharges reported here, the fraction of radiated power during the $\mathrm{H}$-mode phase is determined by gas puffing both deuterium (fixed puff) and neon (feedback control) from a location above the midplane. The discharge shape is single null lower divertor with the $\nabla \mathbf{B}$ ion drift direction towards the $\mathrm{X}$-point. The experimental geometry is shown in Fig. 1. The divertor strike point is positioned near the entrance of the pumping plenum which contains a toroidally continuous liquid helium cryopump for active pumping. The location of divertor diagnostics discussed later in the paper is also shown in Fig. 1.

Feedback control is achieved by using the DIII-D digital plasma control system (PCS) to calculate radiated power in real time using four bolometer channels[3]. An alternative algorithm estimates radiated power using $\mathrm{Ne}^{+7}(77 \mathrm{~nm})$ line emissivity measured by the SPRED spectrometer. Either calculation is compared with a reference waveform for radiated power and the error signal is used for feedback control of the neon gas input rate, shown schematically in Fig. 1. Proportional, integral, and derivative gain (PID) can be optimized by changing parameters in the PCS on a shot-by-shot basis [3].

Data from a discharge in which radiated power was controlled using bolometer signals is shown in Fig. 2. In this case, the reference radiated power was monotonically increasing from 2.0 to $3.7 \mathrm{~s}$. Although feedback control had not been optimized, measured bolometer power calculated by the PCS [Fig. 2(b)] approximates the reference waveform. Note that during the $\mathrm{H}$-mode phase when impurity feedback control was enabled, 2.0 to $3.5 \mathrm{~s}$, the ratio of PCS radiated power calculated in real time to total radiated power from the entire bolometer array was nearly constant [Fig. 2(c)], which allowed feedback control of $\mathrm{P}_{\mathrm{fr}}$. 


\section{Real Time Plasma Control System}

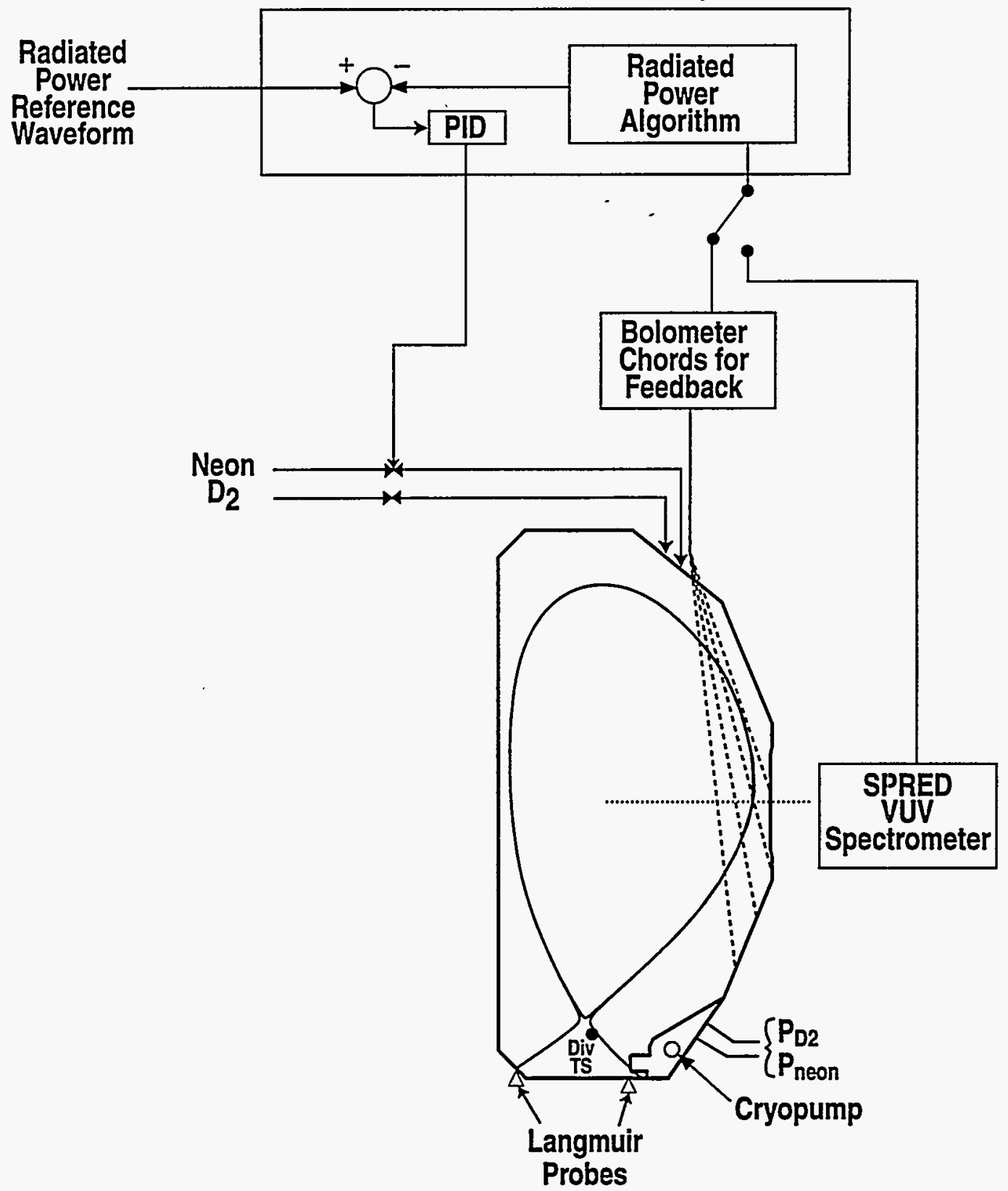

Fig. 1. DIII-D geometry for active impurity feedback control. The separatrix flux surface is shown as a solid line. The outer strike point defined by this flux surface is positioned for pumping with the toroidally symmetric cryopump. Radiated power is calculated using either four channels of the bolometer array or a $\mathrm{Ne}^{+7} \mathrm{u}-\mathrm{v}$ impurity line. Not all channels of profile diagnostics are shown; only the locations of key diagnostics discussed in this paper are indicated. 

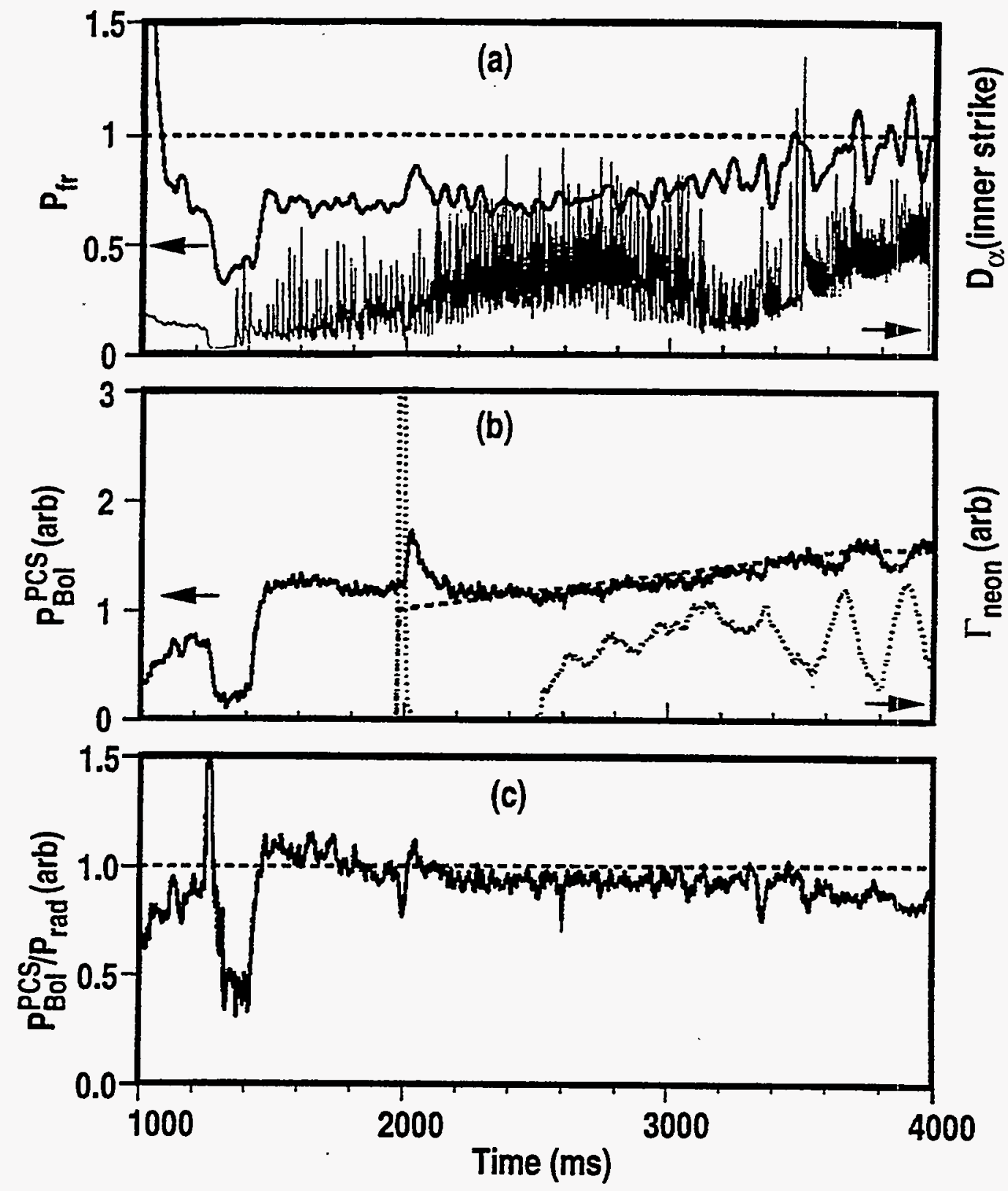

Fig. 2. $P_{f r}$ is controlled by puffing neon during a tokamak discharge ( $\# 86947, I_{p}=$ 1.3 $\mathrm{MA}, \mathrm{B}_{\mathrm{t}}=1.9 \mathrm{~T}, \mathrm{P}_{\mathrm{NBI}}=6.3 \mathrm{MW}$ ). The reference waveform (dashed line) and four channel bolometer radiated power, $\mathrm{P}_{\mathrm{BOl}}^{\mathrm{PCS}}$, are compared in (b). Neon gas puffing rate, $\Gamma_{\text {neon, }}$ is also shown. The ratio of total radiated power, $P_{\text {rad, }}$, to calculated power used by the digital PCS is shown in (c) 


\section{PLASMA DISCHARGES WITH ACTIVE FEEDBACK CONTROL}

In order to test the DIII-D active impurity feedback system, a series of discharges was - initiated, varying both the deuterium and neon gas puff rates. Since the primary goal was to qualify the feedback system, there was no attempt to obtain feedback control at a constant $\mathrm{P}_{\mathrm{fr}}$ for long durations. An example of active impurity feedback control is shown in Fig. 3. Neutral beam power, $\mathrm{P}_{\mathrm{NBI}}=6.3 \mathrm{MW}$, was constant during the time shown. A constant deuterium puff, at $180 \mathrm{~T}-\mathrm{L} / \mathrm{s}$ was initiated at $1.4 \mathrm{~s}$. The outer strike point was positioned at the entrance of the cryopump plenum. Impurity feedback control, using the $\mathrm{Ne}^{+7}$ impurity line radiation, was initiated at $2.0 \mathrm{~s}$. Radiated power increased, in response to the programmed waveform until $\mathrm{P}_{\mathrm{fr}} \approx 1$ at $3.2 \mathrm{~s}$, shown in Fig. 3(b). Shortly after the radiated power exceeded the input power, at $t=3.3 \mathrm{~s}$ in Fig. 3(a), the discharge transitioned back to L-mode. ELM behavior during $\mathrm{H}$-mode is plotted in Fig. 3(a). After a short ELM free phase, Type I large amplitude ELMs [4] begin and continue after deuterium injection begins at $1.4 \mathrm{~s}$. After neon injection commences at $2.0 \mathrm{~s}$, combination ELMs (Type I and Type III) are observed. Finally, when $\mathrm{P}_{\mathrm{fr}}$ reaches approximately 0.9 there is a brief transition back to L-mode ( $2.9 \mathrm{~s}$ in Fig. 3 ) and then Type III ELMs are observed. The uncertainty in total radiated power and $\mathrm{P}_{\mathrm{fr}}$ is estimated to be $10 \%-15 \%$. This is higher than usual due to gas puffing from a toroidal location near the upper bolometer array. The behavior of divertor heat flux measured by an IRTV camera, for which data is plotted in Fig. 3(c), also evolves and decreases during the various phases of gas puffing. During part of the discharge the outer strike point was at the entrance to the cryo pump which is not in the field of view of the IRTV. Hence, only inner strike point peak heat flux is plotted in Fig. 3(c). During neon impurity injection, peak heat flux remains low including the phase with Type III ELMs. Central $Z_{\text {eff }}$, determined from impurity concentrations of neon, carbon, oxygen, and helium and measured by charge exchange recombination radiation in the VUV, increases slightly after neon injection at $2.0 \mathrm{~s}$, then increases further with the onset of Type III ELMs. The change from a combination of Type I and Type III ELMs ( $t<2.9 \mathrm{~s}$ in Fig. 3) to only Type III ELMs does produce an increase in central neon concentration, which is the dominant core impurity. However, $Z_{\text {eff }}(0)$ never exceeds 2.1 in any phase of this discharge, i.e. central Zeff remains relatively low. Finally, we note that after $2.9 \mathrm{~s}$, neutral pressure in the main chamber increases monotonically, as shown in Fig. 3(d). 

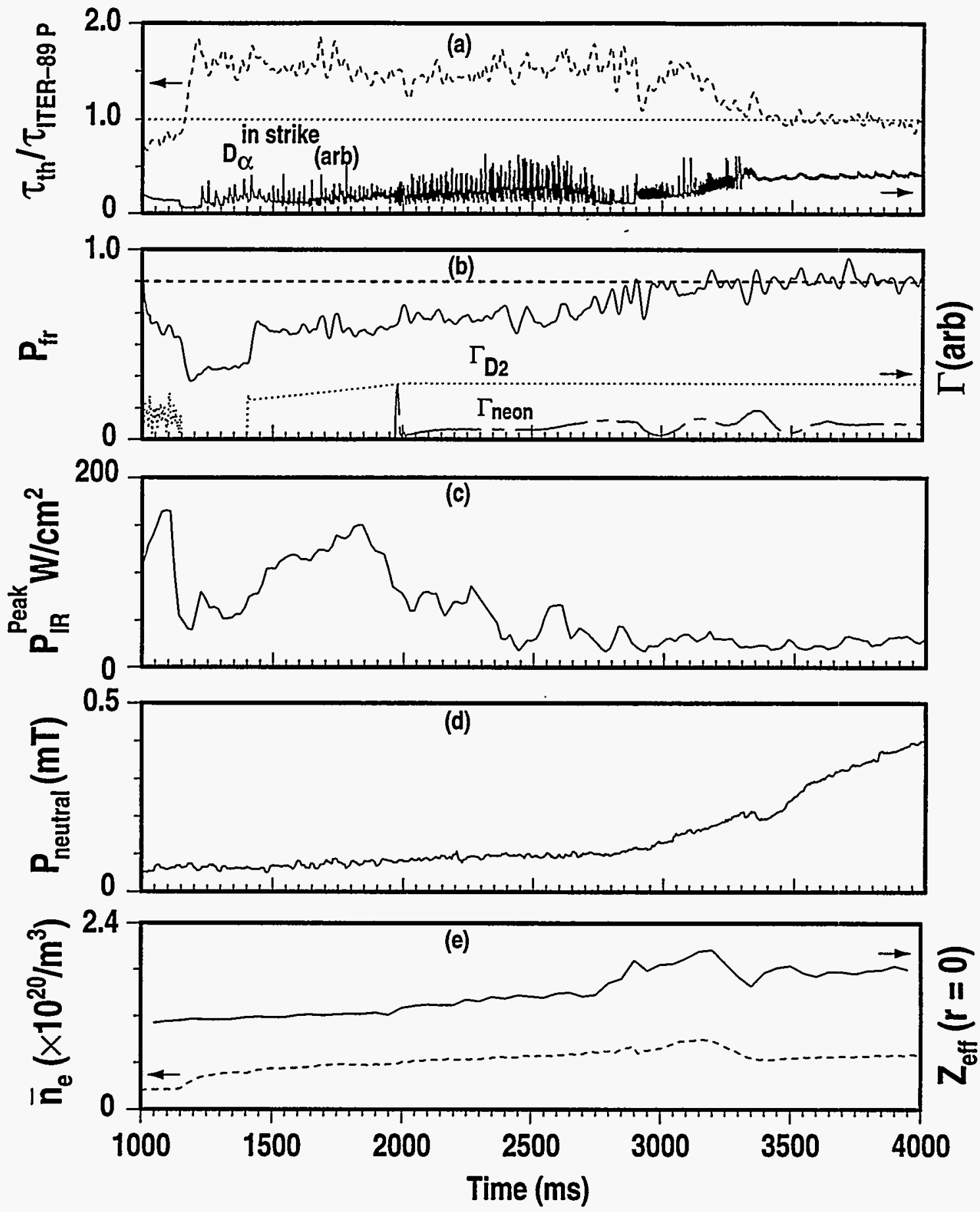

Fig. 3. H-mode confinement is up to $1.6 \times$ ITER89-P during ELMing $H$-mode, (a), in phases of deuterium $\left(G_{D 2}\right)$ and neon $\left(G_{\text {neon }}\right)$ puffing with $P_{f r} \leq 1$, (b). Peak power, $\mathrm{P}_{\mathrm{IR}}^{\mathrm{Peak}}$, is measured by IRTV, (c), for the the inner strike point. Neutral pressure in the main chamber increases during Type III ELMs, and L-mode (d). Central $Z_{\text {eff }}$ and line average density are plotted in (e). Discharge parameters (\#86948) are the same as in Fig. 2. This discharge used neon feedback from a Ne+7 line. 
The change to Type III ELMs at $2905 \mathrm{~ms}$, preceded by a brief L-mode confinement phase, and subsequent low conducted heat to the divertor tiles has characteristics similar to $\mathrm{CDH}$-mode reported recently on the ASDEX-Upgrade device [5,6]. This phase is shown in more detail in Fig. 4 for the same discharge as Fig. 3. After $2.9 \mathrm{~s}$, the increase in radiated power, Fig. 4(a), is from the main chamber. Bolometric profiles during this phase confirm that the increased radiation is not from the divertor, but rather from a radiating mantle around the plasma core. At $2950 \mathrm{~ms}, 3.4 \mathrm{MW}$ is radiated from inside the last closed flux surface (LCFS) excluding the region near the $\mathrm{X}$-point. Before the onset of continuous Type III ELMs, which occurs at $2905 \mathrm{~ms}$ in Figs. 3 and 4, there is a gradual evolution of divertor parameters, e.g. Fig. 4(c-e). Electron temperature, measured by divertor Thomson scattering near the $\mathrm{X}$-point (location is shown in Fig. 1), decreases to $<2 \mathrm{eV}$ at $2800 \mathrm{~ms}$, while electron density (not shown) increases by more than a factor of 2 to $\approx 1 \times 10^{20} / \mathrm{m}^{3}$. Electron density at the inner strike point, measured by a floor Langmuir probe (Fig. 1), steadily decreases from 2.2 to $2.9 \mathrm{~s}$. Although accurate fits of Langmuir probe data to obtain temperature and density were not possible near the outer strike point, the ion saturation current, shown in Fig. 4(e), shows no evidence of ELMs penetrating to the floor probe nearest the outer strike point after $2.9 \mathrm{~s}$. During this phase there is no evidence of these spikes on any Langmuir probe in the floor array, including those at the inner strike point. The Langmuir probe voltage is swept at $250 \mathrm{~Hz}$ and before $2.9 \mathrm{~s}$ in Fig. 4(e) large amplitude spikes are present if the sweep voltage is biased negative during the Type I ELMs, i.e. density at the floor increases during these ELMs.These observations are consistent with detachment of the plasma from 2.9 to $3.3 \mathrm{~s}$ in the divertor region while maintaining $\mathrm{H}$-mode confinement. We note that during this period, the $\mathrm{H}$-factor [Fig. 3(a)] varied from 1.2 to 1.6 , and was actually increasing during the first period of Type III ELMs. Although not shown in Fig. 3, an H-factor of 1.6 is equivalent to JET-DIII-D empirical confinement scaling for these discharges, i.e. $\tau_{E} / \tau_{\text {JET-DIII-D }}=1.0$ for $\mathrm{H}=1.6$. 

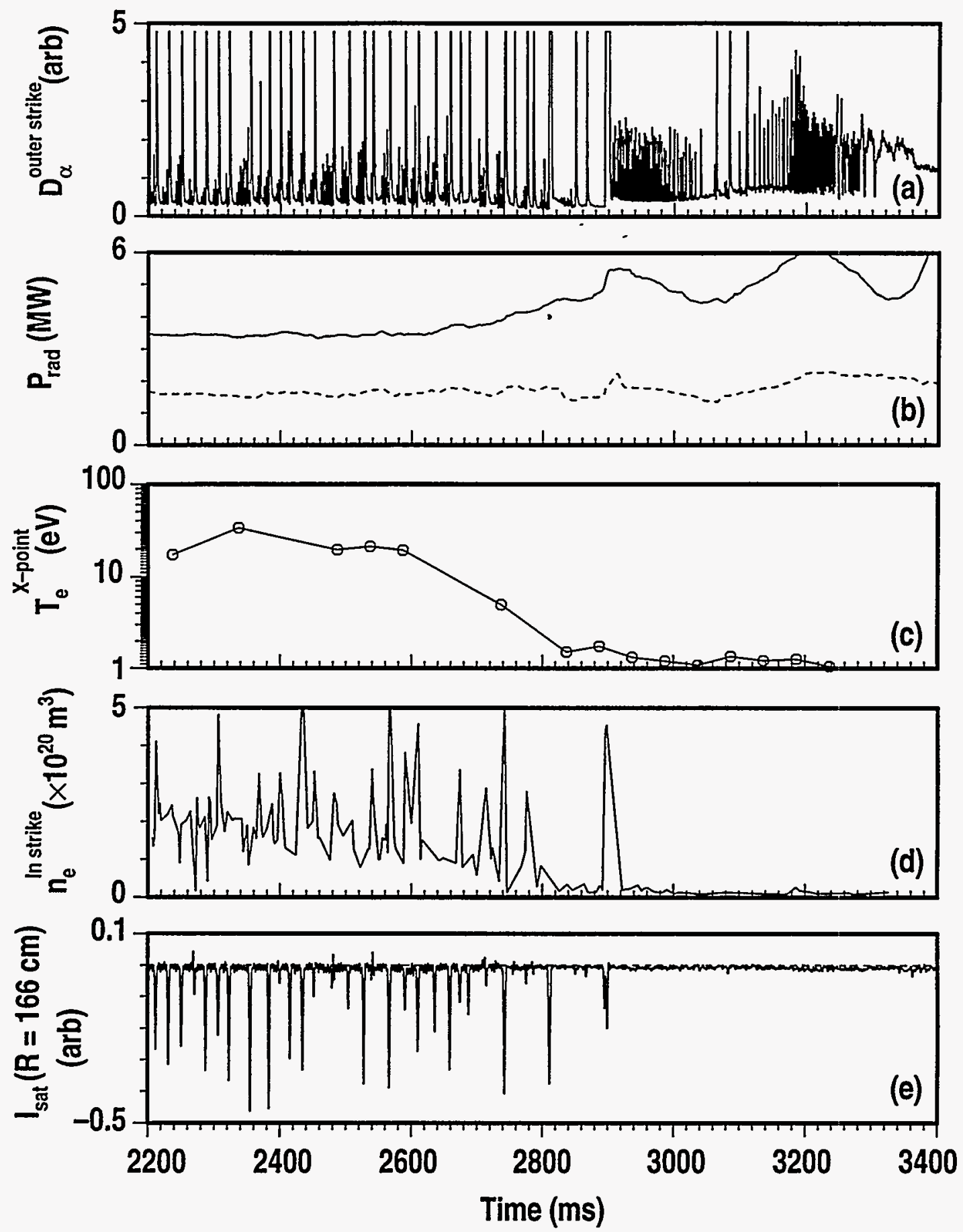

Fig. 4. Same discharge as in Fig. 3, showing the phase with neon puffing: (a) $D_{\alpha}$ at the outer strike point, (b) Radiated power from the mantle (solid line) and divertor (dashed), (c) electron temperature near the X-point, (d) electron density at the inner strike point calculated from a floor Langmuir probe, and (e) ion saturation current from a floor Langmuir probe at $R=166 \mathrm{~cm}$, inside of, but near the outer strike point. 


\section{DISCUSSION}

Active impurity feedback using neon has been successfully demonstrated using either bolometer channels or a neon $\mathrm{u}-\mathrm{v}$ impurity line to control the fraction of radiated power. Although not fully optimized, the DIII-D digital plasma control system has demonstrated the capability of rapid feedback control under evolving conditions such as changing ELM frequency.

The observations of detachment, shown in Fig. 4 and presented in Section 3, are consistent with the $\mathrm{CDH}$-mode observed in ASDEX-U. In this initial one day experiment, only short $\mathrm{CDH}$-mode phases were observed in DIII-D. This was because $\mathrm{P}_{\mathrm{fr}}$ was programmed to monotonically increase during the discharges, e.g. Fig. 2, to rapidly cover parameter space. Hence the radiation limit, $\mathrm{P}_{\mathrm{fr}}=1$, was reached shortly after the $\mathrm{CDH}$-mode was established and the discharge reverted to L-mode confinement. A further reason that the $\mathrm{CDH}$-mode phase may have terminated early was that the main chamber neutral pressure began increasing after detachment. This may be caused by a decrease in pumping efficiency, since thermalized neutral particles are the primary constituents at the cryopump pump inlet after detachment. Future experiments will focus on maintaining high radiated power $\left(\mathrm{P}_{\mathrm{fr}}>\right.$ 0.8 ) in steady state conditions.

Radiation inside the LCFS during the initial $\mathrm{CDH}$-mode phase in Fig. 4 was $3.4 \mathrm{MW}$, or $45 \%$ of the input power, $\mathrm{P}_{\text {tot }}$. The power crossing the LCFS is then estimated to be $4.1 \mathrm{MW}$, which is significantly higher than the threshold power for the $\mathrm{L}$ to $\mathrm{H}$ transition which is estimated from empircal scaling to be $\leqslant 2 \mathrm{MW}$ [7]. We note, however that due to the effects of gas puffing near the upper bolometer array viewing port, the contribution of radiated power in the X-point region which was inside the LCFS could not be measured and this power was excluded from the calculation. The contribution of this radiated power would decrease the power flowing across the LCFS to a value closer to the $\mathrm{L}$ to $\mathrm{H}$ threshold power as observed on ASDEX-U CDH-mode discharges [5,6].

Although one discharge has been discussed in detail, similar behavior was observed on other discharges. The time of the $\mathrm{H}$ to $\mathrm{CDH}$ transition varied depending upon the rate of rise of programmed radiated power, however this transition is only observed if $\mathrm{P}_{\mathrm{fr}} \geq 0.9$. We note that these discharges exhibited $q$ profiles which had weak negative central shear (NCS) [8] and $q_{\min }>1$. Whether NCS is necessary to obtain the $\mathrm{CDH}$-mode will require further experiments.

Particle confinement time is an important issue for fusion reactors: hydrogenic particles must have sufficient time to react while impurity confinement time must be low to avoid 
central accumulation. Particle confinement is difficult to measure directly in devices such as DIII-D with a divertor configuration, and a discussion of particle confinement is beyond the scope of this paper. Previous work in DIII-D has shown that the ELM free global particle confinement time is of the same order as the energy confinement time $[9,10]$. Changes in particle confinement time during ELMing $\mathrm{CDH}$-mode have not yet been measured or calculated.

Future work in the area of active impurity feedback control will include: the use of different impurity gases, steady state $\mathrm{CDH}$-mode, other high $P_{\mathrm{fr}}$ regimes such as TEXTOR L-mode enhanced confinement discharges, a better algorithm for calculating $\mathrm{P}_{\mathrm{fr}}$ in the mantle, and optimization of energy confinement while maintaining $Z_{\text {eff }}<2$. 


\section{REFERENCES}

[1] J. Winter, H.G. Esser, G.L. Jackson, et al., Phys. Rev Lett. 71 (1993) 1549.

[2] J. Ongena, et al., Plasma Phys. Contr. Fus. 83 (1996)279.

[3] M. Walker, J.R. Ferron, B. Penaflor, et al., Proc. 16th IEEE/NPS Symp. on Fusion Engr., Champagne, IL, USA (1995).

[4] E.J. Doyle, et al., Phys. Fluids B3 (1991)2300.

[5] O. Gruber, A. Kallenbach, M. Kaufmann, et al., Phys. Rev. Lett. 74 (1995) 4217.

[6] A. Kallenbach, R. Dux, V. Mertens, et al., Nuc. Fus. 35 (1995) 1231.

[7] ITER Working Group on Confinement Databases and Modeling, Bull Am Phys. Soc. 40 (1995) 1726.

[8] E.A. Lazarus, G. Navratil, C.M. Greenfield, et al., submitted to Nuc. Fus. (1996).

[9] G.L. Jackson, D.R. Baker, K.L. Holtrop, et al., J. Nucl. Mater. 220-222(1995)173

[10] L.W. Owen, R. Maingi, D.K. Lee, et al., J. Nucl. Mater. 220-222(1995)315 


\section{ACKNOWLEDGMENTS}

Work supported by U.S. Department of Energy undér Contract Nos. DE-AC0389ER51114, W-7405-ENG-48, and DE-AC05-96OR22464. 